\title{
Clinical Presentation of Malnourished Patients With Pneumonia Requiring Prolonged Ventilatory Support
}

\author{
Dina Johar ${ }^{\mathrm{a}, \mathrm{b}}$, e , Andrew G. Day ${ }^{\mathrm{c}}$, Ekhard E. Ziegler ${ }^{\mathrm{d}}$
}

\begin{abstract}
Background: Prolonged exposure to oxygen during ventilatory support is likely to generate physiological abnormalities in the lungs of critically ill infants with bronchopneumonia. The induced physiological changes could impact the growth of young infants and could promote morbidity and mortality of susceptible patients. This article addresses the relationship of prolonged ventilation, severity of infection and type of feeding with growth of young infants and how this could promote morbidity and mortality of susceptible patients.
\end{abstract}

Methods: In this observational study, we assessed the clinical course of infectious pneumonia and its association with nutritional status, relative growth and lung functions of newborn and young infants with severe pneumonia requiring ventilatory support (group 1, $\mathrm{N}=$ 38). Patients were studied longitudinally to assess the association of weight and height $\mathrm{z}$ scores with blood proteins, ceruloplasmin and copper. Ventilated patients were compared with non-ventilated patients (group 2, $\mathrm{N}=19)$ and healthy controls $(\mathrm{C}, \mathrm{N}=18)$.

Results: On admission, patients exhibited statistically lower blood protein, ceruloplasmin and copper levels compared to controls. Prolonged exposure to oxygen in G1 patients induced a steady state of hypoalbuminemia compared to zero time. The groups differed with regard to growth characteristics, with patients in G1 tending to have lower $\mathrm{z}$ scores for weight and height than group 2 and controls. Recurrent infection rates and duration of ventilation were consistently worse among patients with indicators of malnutrition.

Manuscript accepted for publication May 06, 2016

${ }^{a}$ Ain Shams University Faculty of Women for Arts, Sciences and Education, Heliopolis, Cairo, Egypt

${ }^{b}$ Department of Physiology and Pathophysiology, College of Medicine Faculty of Health Sciences, University of Manitoba, Winnipeg, Manitoba, Canada

${ }^{\mathrm{c}}$ Clinical Research Centre, Kingston General Hospital, 76 Stuart Street, Kingston, Ontario, K7L 2V7, Canada

${ }^{\mathrm{d} F o m o n}$ Infant Nutrition Unit, Department of Pediatrics, 200 Hawkins Dr., Iowa City, IA 52242, USA

${ }^{\mathrm{e}}$ Corresponding Author: Dina Johar, Department of Physiology and Pathophysiology, College of Medicine Faculty of Health Sciences, University of Manitoba, 432 Basic Medical Sciences Building, 745 Bannatyne Avenue, Winnipeg, MB R3E 0J9, Canada. Email: dinajohar@gmail.com

doi: http://dx.doi.org/10.14740/ijcp249w
Conclusion: Patients who administered supplemental oxygen via mechanical ventilation tended to have poorer nutritional status than patients who have not been ventilated and healthy controls

Keywords: Pneumonia; Weight for height z score; Height for age z score; Weight for age z score; Mechanical ventilation; Under-five mortality

\section{Introduction}

Morbidity and mortality from acute lower respiratory infections (pneumonia) are high in developing countries [1]. In Egypt, $15-20 \%$ of childhood deaths in 2000 were attributed to pneumonia [2]. Pneumonia is the deadliest acute respiratory infection [3]. In 2008, the under-five mortality rate was 21.8 per 1,000 live births. Pneumonia and diarrhea caused $15 \%$ and $13 \%$, respectively, of deaths in this age group in $2000-2003$ [4]. Malnutrition [5], young age [6,7], low birth weight, lack of breast feeding [8], compromised immune response [9] and lack of vaccination [10] are strong predisposing factors for pneumonia in developing countries. Malnutrition aggravates the severity of diarrhea and pneumonia and increases mortality from these diseases [11].

Respiratory distress (RD) due to infectious pneumonia indicates that the illness is of critical severity. Severe grades of RD include acute lung insufficiency (ALI) and acute respiratory distress syndrome (ARDS). Inadequate ventilation is reflected in abnormal blood gas values. Paradoxically, the very treatment modality that is necessary for treatment in severe respiratory illness, i.e., oxygen, has potential adverse effects on patients. Prolonged exposure to oxygen during ventilatory support is likely to generate physiological abnormalities in the lungs of critically ill infants with bronchopneumonia. We therefore assessed the association of prolonged exposure to oxygen with the clinical course of infectious pneumonia, nutritional status, relative growth and lung functions of newborn and young infants with severe pneumonia requiring ventilatory support.

Limited data are available for Egypt regarding the association between nutritional status and the severity of RD in infants hospitalized with pneumonia. Worldwide, low weight-for-age (underweight) and other markers of protein-energy malnutri- 
tion are predictors, along with age, temperature, respiratory rate and increased respiratory effort, of the outcome of serious bacterial infections [11].

According to WHO [12], more than $30 \%$ of children under 5 years of age worldwide are malnourished. In Egypt, 23.8\% and $5.4 \%$ of children under five are stunted or underweight, respectively. In Egypt, morbidity and mortality in children less than 5 years of age with infectious pneumonia remain high, but exact statistics are not available. The clinical outcome depends on the prompt delivery of antibiotics and of nutrients via the intravenous (IV) and nasogastric routes, and also on the availability of ventilatory assistance. In underdeveloped countries, lack of standardization of hospital care hinders the optimal application of proven effective strategies. The present study concerned Egyptian children less than 5 years of age who were hospitalized with RD due to bronchopneumonia. The study assessed the impact of 1) growth parameters as indicators of chronic nutritional status, and 2) specific nutritional deficiencies on the clinical course of pneumonia.

\section{Patients and Methods}

This was an observational study in which growth and nutritional status were assessed in patients with community-acquired pneumonia. The purpose of the study and any special procedures were explained to the child's mother or a primary caregiver or next to kin and verbal consent to enrollment was obtained. Consent was obtained as well from the treating physician. In accordance with local practice at the time when the study was carried out, the study was approved by Cairo University Children's Hospital authorities and was part of the hospital chart. Both the hospital and Ain Shams University in Cairo reviewed and approved the research proposal. The patients comprised all those admitted between December 2002 and February 2003 who had RD on admission and received a diagnosis of bronchopneumonia. Patients were grouped into two groups based on the severity of the RD: group 1 (G1) had more severe pneumonia defined by the requirement for oxygen therapy; group $2(\mathrm{G} 2)$ had less severe pneumonia and did not require oxygen therapy. Controls (group 3, C) were healthy infants and children who were attending the outpatient clinic of the hospital to receive periodical vaccinations or were in the hospital recuperating from acute illnesses. The study plan was to assess patients in $\mathrm{G} 1$ and $\mathrm{G} 2$ on admission and to perform repeat assessments on one or two occasions after variable intervals. Control subjects were assessed only once using data obtained in the course of their medical management. The number of patients (convenience sample) was determined by the number of patients who were admitted and met the study criteria during the study period selected.

The objectives of the study were to assess growth and nutritional status of infants with bronchopneumonia and to determine any association of nutritional status with the course of the illness; to correlate anthropometric measures with concentrations of plasma proteins on admission; to assess the impact of prolonged use of oxygen on concentrations of plasma proteins; and to assess the effect of confounding factors such as diar-

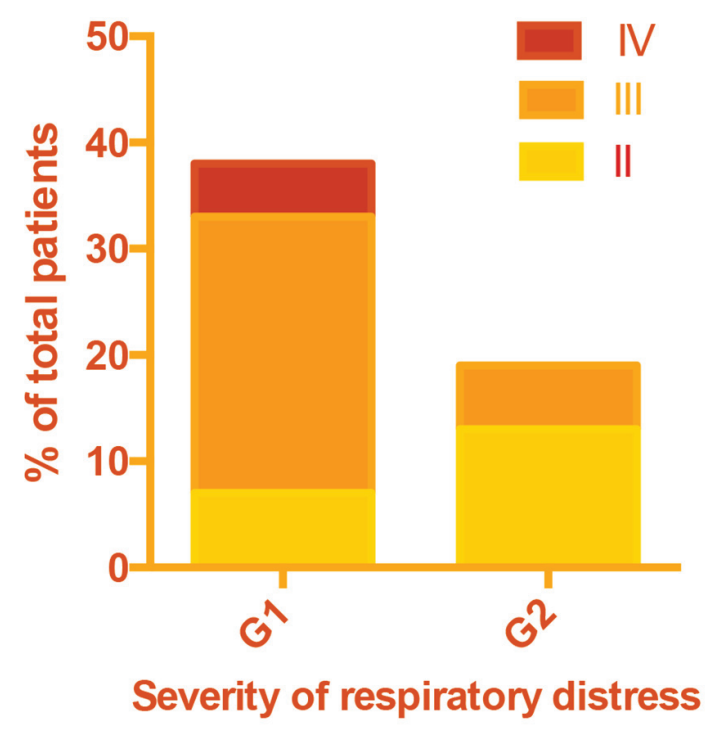

Figure 1 . Severity of respiratory distress in patient groups.

rhea, fever, low birth weight and absence of breastfeeding on the course and severity of the illness.

Study subjects were consecutively admitted patients from December 1, 2002 to February 28, 2003 to Cairo University Pediatric Hospital who received a diagnosis of bronchopneumonia and met the inclusion criteria listed below. The 57 patients (30 males and 27 females) were between 23 days and 48 months old. The control group (C) included 18 healthy infants and children of either gender who ranged in age from 5 to 36 months.

Pneumonia was classified as very severe (grade IV) if patients were unable to drink, had abnormal sleep or convulsions or were dehydrated; severe (grade III) if patients showed chest retractions; and mild (grade II) if there was tachypnea but no retractions (Fig. 1). Tachypnea was defined as $>50$ breaths $/ \mathrm{min}$ in infants and $>40$ breaths $/ \mathrm{min}$ in older patients. Chest retractions were frequent and were predictive of bronchopneumonia, particularly in protein-energy malnourished subjects. A diagnosis of bronchopneumonia was made if there was 1) a history of cough with or without fever, 2) rales and/or mucopurulent discharge, and 3) two or more of the following signs on chest auscultation: diminished air entry, rapid bronchial breathing, crepitations or wheezing. Laboratory results confirmed that most pneumonias were bacterial in etiology. All patients had a confirmatory chest X-ray showing patchy infiltrates in more than one lobe, and many patients had positive blood cultures growing mostly Streptococcus pneumoniae. Empirical antimicrobial therapy was started with one or two antibiotics until blood culture results were available and therapy was modified accordingly.

Severe respiratory failure was defined as partial pressure of oxygen $\left(\mathrm{PaO}_{2}\right)<60 \mathrm{~mm} \mathrm{Hg}$, or oxygen saturation $\left(\mathrm{SaO}_{2}\right)$ $<90 \%$; or partial pressure of $\mathrm{CO}_{2}\left(\mathrm{PaCO}_{2}\right)>8 \mathrm{kPa}$; or $\mathrm{pH}<$ 7.25 while breathing room air. Acute lung injury (ALI) and acute respiratory distress syndrome (ARDS) were defined by an arterial oxygen tension $\left(\mathrm{PaO}_{2}\right) /$ fraction of inspired oxygen 


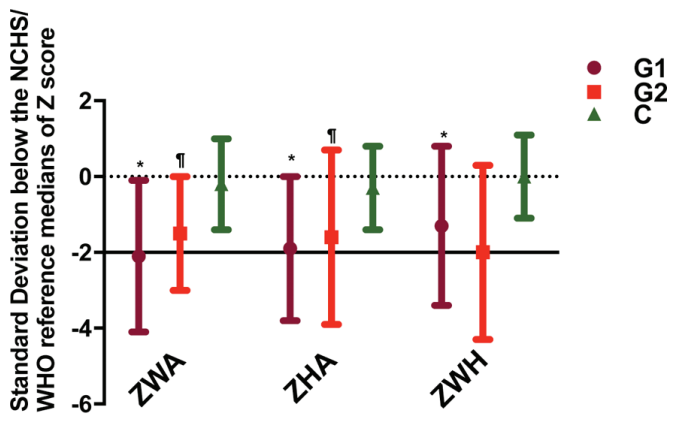

Growth Standards. "Difference between G1 and C,
ๆ Difference between G2 and C, significant at
alpha=0.05

Figure 2. Cutoffs of $z$ scores definitions of normal versus undernutrition, wasting and stunting according to $\mathrm{WHO} / \mathrm{NCHS}$.

$\left(\mathrm{FIO}_{2}\right)(\mathrm{P} / \mathrm{F}$ ratio) $300-200$ and $\leq 200$, respectively [13]. Supplemental oxygen and mechanical ventilation were used with the aim to bring $\mathrm{SaO}_{2}$ to $90-100 \%$. Patients were included in group G1 if they had respiratory failure that required supplemental oxygen therapy with or without positive pressure support. Patients were included in group G2 if they did not require oxygen therapy. Zero time was defined as any point before oxygen was supplied.

The techniques recommended by Jelliffe [14] were used for measuring weight and length. The length of infants was accurately measured on a recumbent length board. Measured weight and length were converted to $\mathrm{z}$ scores of weight-for-age (WA), height-for-age (HA) and weight-for-height (WH) using the National Center for Health Statistics growth standards [15].

Undernutrition involved any of the following: 1) Underweight and severe underweight were defined as -2 and -3 SD below the NCHS/WHO reference median of weight-for-age (ZWA score). 2) Wasting and severe wasting were defined as -2 and -3 SD below the NCHS/WHO reference median of weight-for-height (ZWH score), respectively. 3) Stunting and severe stunting were defined as -2 and -3 SD below the NCHS/ WHO reference median of height-for-age (ZHA score), respectively. Figure 2 presents the cutoffs of $z$ scores definitions of normal versus undernutrition, wasting and stunting according to $\mathrm{WHO} / \mathrm{NCHS}$. Upon admission, most patients received intravenous (IV) fluids, which were gradually replaced by oral fluids as the patient's condition improved. Fluid intake for G1 patients in $24 \mathrm{~h}$ typically was set at a rate of $100 \mathrm{~mL} / \mathrm{kg}$ for the first $10 \mathrm{~kg}$ plus $50 \mathrm{~mL} / \mathrm{kg}$ for the second $10 \mathrm{~kg}$ plus $20 \mathrm{~mL} /$ $\mathrm{kg}$ for the third $10 \mathrm{~kg}$. IV fluids consisted of $12 \%$ glucose, 10 $\mathrm{mEq} / \mathrm{L}$ potassium, $30 \mathrm{mEq} / \mathrm{L}$ sodium and $40 \mathrm{mEq} / \mathrm{L}$ chloride.

Arterial blood gas analysis was performed to monitor ventilation. Oxygen was delivered using a head box, mask, nasal cannula or mechanical ventilator. Oxygen saturation of the blood was measured using pulse oximetry.

Blood samples were drawn from G1 patients after 24 $48 \mathrm{~h}$ of oxygen administration. In G2 patients, blood samples were drawn 24 - $48 \mathrm{~h}$ after hospital admission. A $5 \mathrm{~mL}$ venous blood sample was drawn by antecubital venipuncture. The heparinized blood was immediately centrifuged at 3,000 rpm for $15 \mathrm{~min}$ at room temperature. Plasma was used for the determination of albumin according to Grant and Kachmar [16] and of total protein according to Henry et al [17]. Criterion for exclusion from analysis was contamination of plasma by blood. Blood hemoglobin concentration was determined by photometric quantitation of cyanmethemoglobin at $540 \mathrm{~nm}$ [18]. Plasma ceruloplasmin (Cer) was determined by its oxidase activity according to Schosinsky et al [19]. Plasma copper was assayed using the method described by Abe et al [20]. Blood gas determinations were made using arterialized blood samples.

\section{Statistical analysis}

Continuous variables were compared between groups us-
A

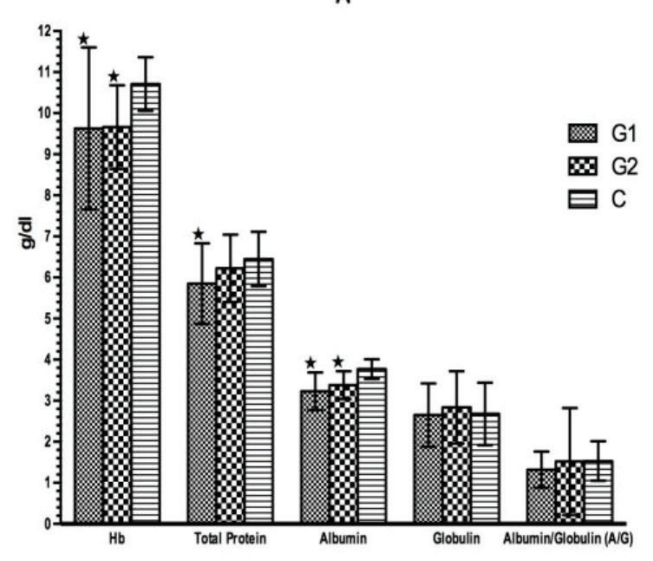

B

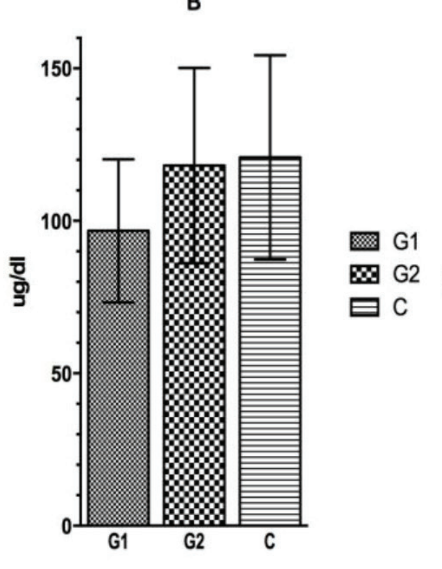

C

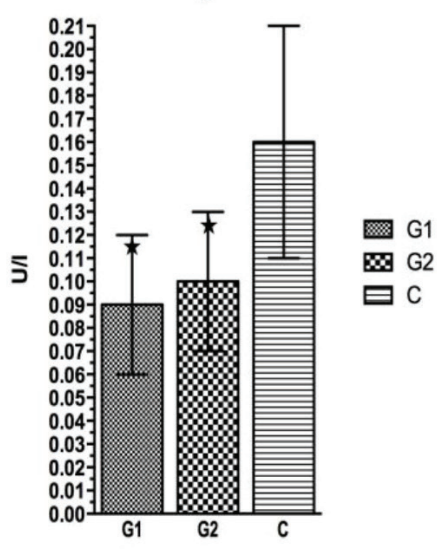

$\star$ significant difference from $\mathrm{C}, \mathrm{p} \leq \mathrm{0.05}$

Figure 3. (A) Hemoglobin and plasma proteins at time of admission. (B) Plasma copper at time of admission. (C) Plasma ceruloplasmin at time of admission. 
Table 1. Subjects' Clinical Characteristics at Time of Admission

\begin{tabular}{|c|c|c|c|}
\hline & G1 $(\mathrm{N}=38)$ & G2 $(N=19)$ & $C(N=18)$ \\
\hline Age (months)*ף & $9.6 \pm 10.9$ & $5.2 \pm 4.6$ & $17.1 \pm 9.6$ \\
\hline Weight $(\mathrm{kg})^{* \pi}$ & $6.2 \pm 3.4$ & $5.8 \pm 2.1$ & $9.9 \pm 2.3$ \\
\hline Height/length $(\mathrm{cm})^{* \pi}$ & $63.5 \pm 11.6$ & $60.2 \pm 9.1$ & $77.4 \pm 9.0$ \\
\hline $\mathrm{ZWA} * \pi$ & $-2.1 \pm 2.0$ & $-1.5 \pm 1.5$ & $-0.2 \pm 1.2$ \\
\hline ZHA* & $-1.9 \pm 1.9$ & $-1.6 \pm 2.3$ & $-0.3 \pm 1.1$ \\
\hline $\mathrm{ZWH}^{*}$ & $-1.3 \pm 2.1$ & $-0.2 \pm 2.3$ & $-0.0 \pm 1.1$ \\
\hline Male gender & $21(55.3)$ & $9(47.4)$ & $7(38.9)$ \\
\hline Low birth weight & $7(18.4)$ & $2(10.5)$ & $0(0.0)$ \\
\hline Feeding practice after birth: breastfed ( \pm supplementation $) *$ & $23(60.5)$ & $16(84.2)$ & $18(100.0)$ \\
\hline Formula only & $15(39.5)$ & $3(15.8)$ & $0(0.0)$ \\
\hline Previously hospitalized & $8(21.1)$ & $2(10.5)$ & \\
\hline First episode & $26(68.4)$ & $15(78.9)$ & \\
\hline Recurrent infection & $12(31.6)$ & $4(21.1)$ & \\
\hline \multicolumn{4}{|l|}{ Severity of $\mathrm{RD}^{\dagger}$} \\
\hline II & $7(18.4)$ & $13(68.4)$ & \\
\hline III & $26(68.4)$ & $6(31.6)$ & \\
\hline IV & $5(13.2)$ & 0 & \\
\hline Route of feeding ${ }^{\dagger}$ & & $\S$ & \\
\hline IV & $14(36.8)$ & $9(50.0)$ & \\
\hline NG & $1(2.6)$ & $8(44.4)$ & \\
\hline Both & $23(60.5)$ & $1(5.6)$ & \\
\hline Vomiting $^{\dagger}$ & $6(15.8)$ & $9(47.4)$ & \\
\hline Diarrhea & $5(13.2)$ & 7 (36.8) & \\
\hline Fever & $34(89.5)$ & $14(73.7)$ & \\
\hline
\end{tabular}

†Difference between G1 and G2 significant at alpha $=0.05$. *Difference between G1 and C significant at alpha $=0.05$. "Difference between $\mathrm{G} 2$ and $\mathrm{C}$ significant at alpha $=0.05$. §One missing observation. Values are mean $\pm \mathrm{SD}$, number of subjects with percent in parentheses.

ing either one-way analysis of variance with Tukey-Kramer correction for three pairwise comparisons, or by the independent $t$-test for characteristics only available for G1 and G2. Categorical characteristics were compared between groups by Fisher's exact test. The association between the indicators of malnutrition and binary pneumonia morbidity outcomes (death, recurrent illness, other illness) were tested by Fisher's exact test and measured by odds ratios with exact $95 \%$ confidence intervals after pooling G1 and G2. Duration of ventilation was compared between indicators of malnutrition by the ratio of geometric means with testing by the $t$-test on the log scale due to its log-normal distribution. The within-patient trends of plasma protein levels over time for patients on oxygen therapy (G1) were estimated by the random coefficients model with random patient-specific intercepts and slopes to account for the irregular (and sometimes repeated) longitudinal measurements per patient.

Due to the small sample size and exploratory hypothesis generating nature of this study, we did not attempt to con- trol for potential confounders and did not adjust $\mathrm{P}$ values (all two-sided) for the multiplicity of tests. All analyses were performed using SAS Version 9.3 (SAS Institute Inc., Cary, NC, USA). Figures 1-3 were generated using GraphPad Prism version 7.

\section{Results}

\section{Nutritional status}

Data on patients' growth, anthropometric and clinical characteristics at the time of hospital admission are summarized in Table 1 and Figure 2. The control group was significantly older than G1 and G2. The groups differed with regard to growth characteristics, with patients in G1 and G2 showing significantly lower $\mathrm{z}$ scores for all anthropometric variables than patients in the control group. G1 had consistently, but not always significantly, lower z scores than G2. 
Table 2. Association Between Malnutrition and Pneumonia Morbidity (All Patients)

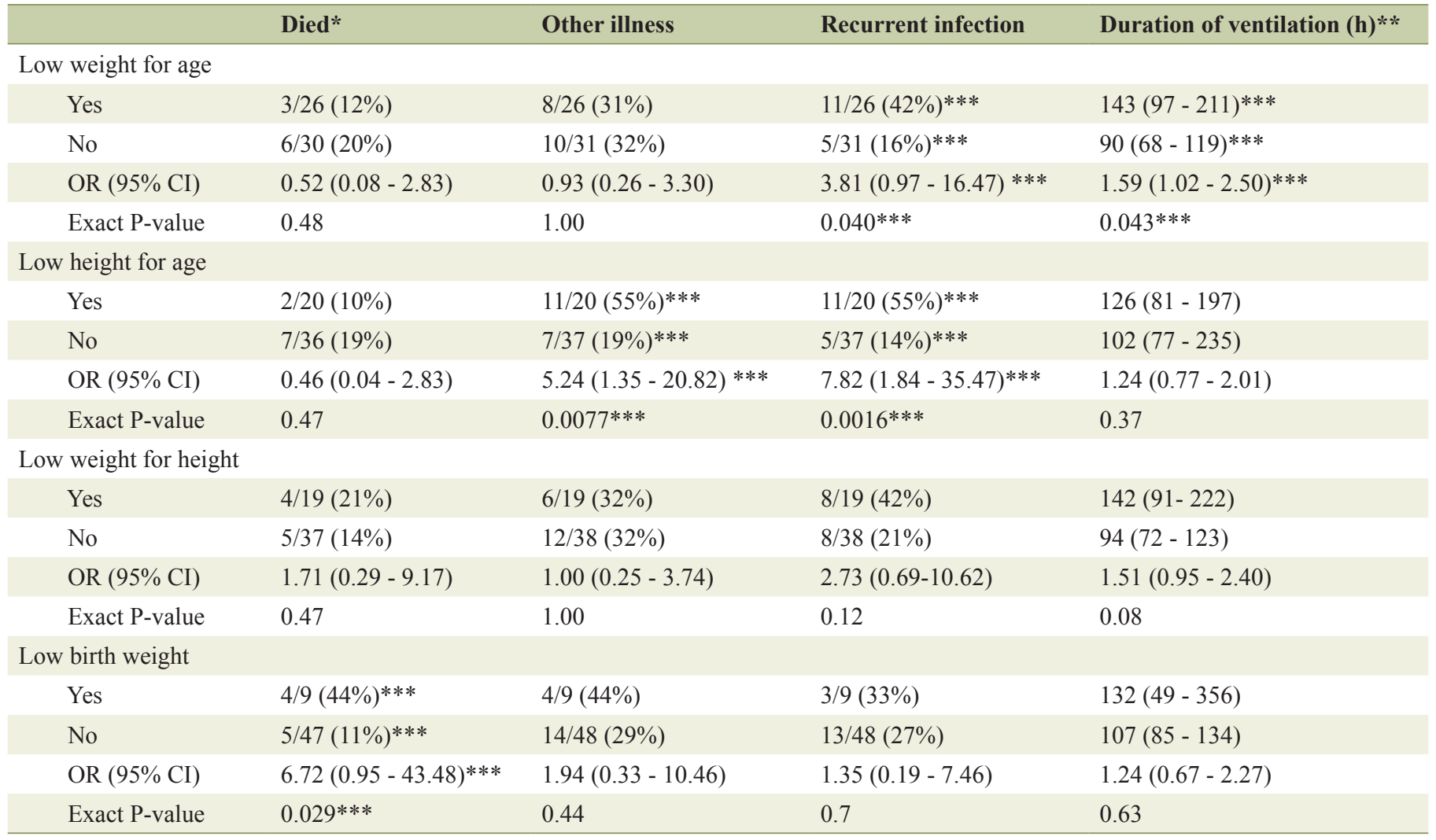

*Death status is missing for one patient, so only 56 patients are included. **Duration of ventilation is reported as geometric means with $95 \%$ confidence intervals within groups, comparison between groups by ratio of geometric means. ${ }^{* *}$ Statistically significant associations.

Although not statistically significant (G1 vs. $\mathrm{C}, \mathrm{P}=0.08)$, low birth weight was most common among G1 patients $(18 \%)$ followed by $\mathrm{G} 2$ patients $(11 \%)$ and was not present among control patients $(0 \%)$. G1 had the lowest rate of breastfeeding $(60 \%)$ followed by $\mathrm{G} 2$ patients $(84 \%)$ while all $\mathrm{C}$ patients were breastfed ( $\mathrm{G} 1$ vs. $\mathrm{C}, \mathrm{P}=0.001)$. All subjects belonged to lower socioeconomic groups.

Although rates of prior hospitalization and prior pneumonia were approximately twice as high in G1 as G2, this difference was not statistically significant due to the small sample size (Table 1). As intended, G1 included all patients with disease severity IV and a greater proportion with severity III than G2 $(\mathrm{P}<0.001)$ (Fig. 1). A total of nine study patients died. Eight of them belonged to G1.

Of the patients, nine presented with severe forms of rickets, one had rickets and cardiomyopathy, two had anemia, one had jaundice, one had a left shift in the differential white cell count, one needed a blood transfusion for severe anemia, one presented with severe malnutrition with anemia and rickets and one presented with delayed development together with anemia and rickets. One patient acquired pneumonia in the hospital after aspiration of gastric contents. Vomiting and diarrhea were more common among G2 patients than among G1 patients $(\mathrm{P}=0.023$ and 0.081 , respectively). Although not statistically significant, both fever and death tended to be more common among G1 patients than G2 patients $(\mathrm{P}=0.14$ and
0.25 , respectively)

\section{Biochemical parameters}

The mean blood chemical values are presented in Figure 3. There was no significant difference in any of the plasma proteins between the two patient groups on admission. Both patient groups showed significantly lower concentrations of albumin, $\mathrm{Hb}$ and $\mathrm{Cer}$ on admission compared to $\mathrm{C}$ patients. In all three groups, there was a high prevalence of low Hb levels $(<10.5 \mathrm{~g} /$ dL, 0 - 9 months; < 10 g/dL, 9 - 12 months; < 11 g/dL, above 1 year) on admission. Twenty-six percent of G1 patients suffered from moderate hypoalbuminemia and $34.2 \%$ had deficient total protein levels on admission $(<5 \mathrm{~g} / \mathrm{dL}$, up to 1 year; $<5.5 \mathrm{~g} / \mathrm{dL}$, 1 - 4 years). The prevalence of hypoproteinemia and hypoalbuminemia was higher in G1 than in G2 and in C, respectively.

The associations between nutritional status and pneumonia morbidity are summarized in Table 2 and Figure 4. Low birth weight was associated with an increased risk of death $(\mathrm{P}$ $=0.029)$, but low ZWA, ZHA and ZWH were not associated with mortality. Low ZHA was associated with higher rates of recurrent infection $(\mathrm{P}=0.002)$ and other illness $(\mathrm{P}=0.008)$. Low ZWA was associated with increased rates of recurrent infection $(\mathrm{P}=0.040)$ and increased duration of ventilation $(\mathrm{P}=0.043)$. There were no other statistically significant as- 


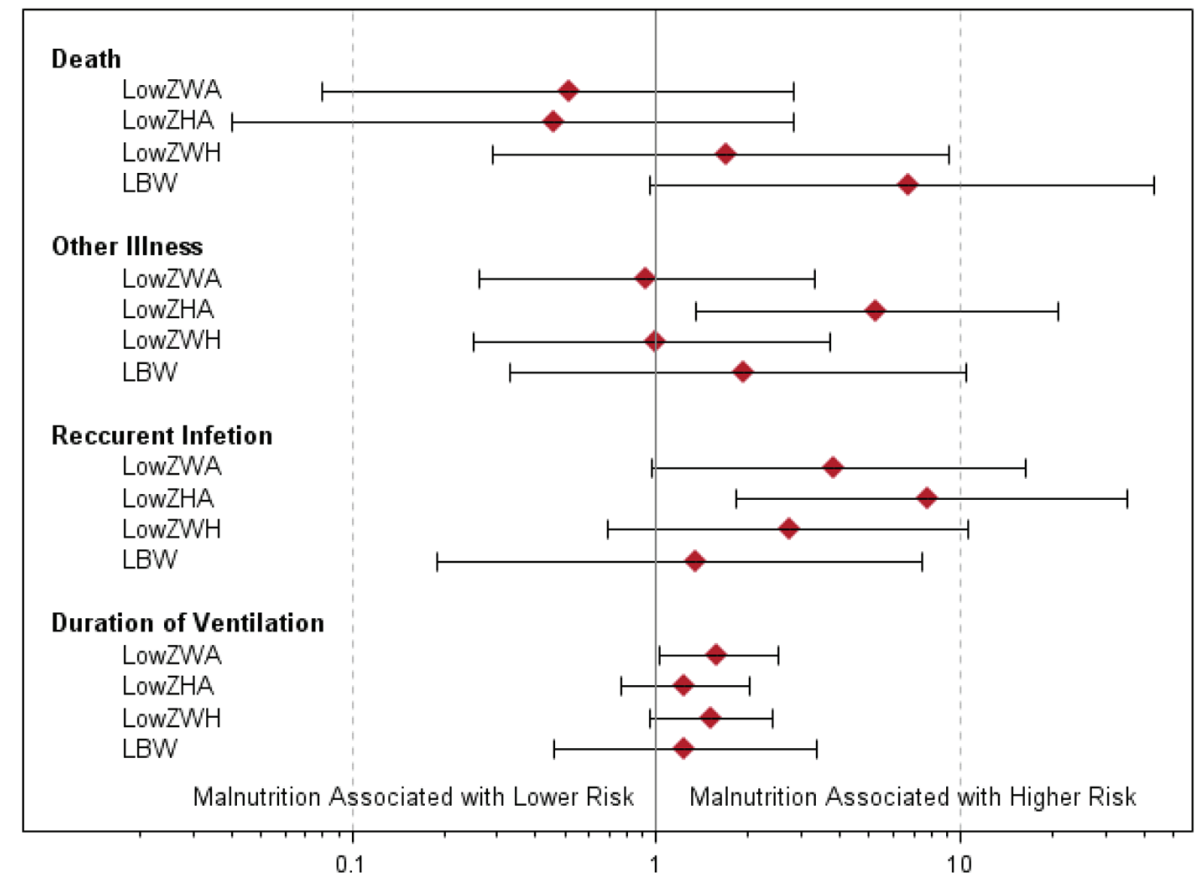

Figure 4. Odds ratios and exact $95 \%$ confidence intervals of associations between measures of malnutrition and death, other illness and recurrent infection. For duration of ventilation, the ratios of geometric means with $95 \%$ confidence intervals are given.

sociations between indicators of malnutrition and pneumonia morbidity. However, recurrent infection rates and duration of ventilation were consistently worse among patients with indicators of malnutrition.

The association of ventilation with plasma proteins is depicted longitudinally in Figure 5. In G1 patients, plasma albumin decreased significantly over time with a slope of -0.075 $\pm 0.02 \mathrm{~g} / \mathrm{dL} /$ day $(\mathrm{P}=0.005)$. The $\mathrm{A} / \mathrm{G}$ ratio also followed a decreasing trend since globulin was stable over time.

The median duration of exposure of G1 patients to oxygen was $101 \mathrm{~h}$. Arterial blood gases are summarized in Table 3. In $\mathrm{G} 1$, the hourly change of arterial blood $\mathrm{pH}$ was significantly greater than zero time (0.000157 units/h, $\mathrm{P}=0.037) . \mathrm{PaO}_{2}$,
$\mathrm{SaO}_{2}$ and $\mathrm{FIO}_{2}$ were elevated similarly but insignificantly from zero time. $\mathrm{HCO}_{3}, \mathrm{P} / \mathrm{F}$ ratio and $\mathrm{PaCO}_{2}$ were insignificantly reduced from zero time. Significant differences between G1 and $\mathrm{G} 2$ patients in $\mathrm{HCO}_{3}$ and $\mathrm{PaCO}_{2}(\mathrm{P}=0.001$ and $\mathrm{P}=0.003)$ were observed.

\section{Discussion}

\section{Growth and nutritional status}

Anthropometric measurements were consistently low in pa-
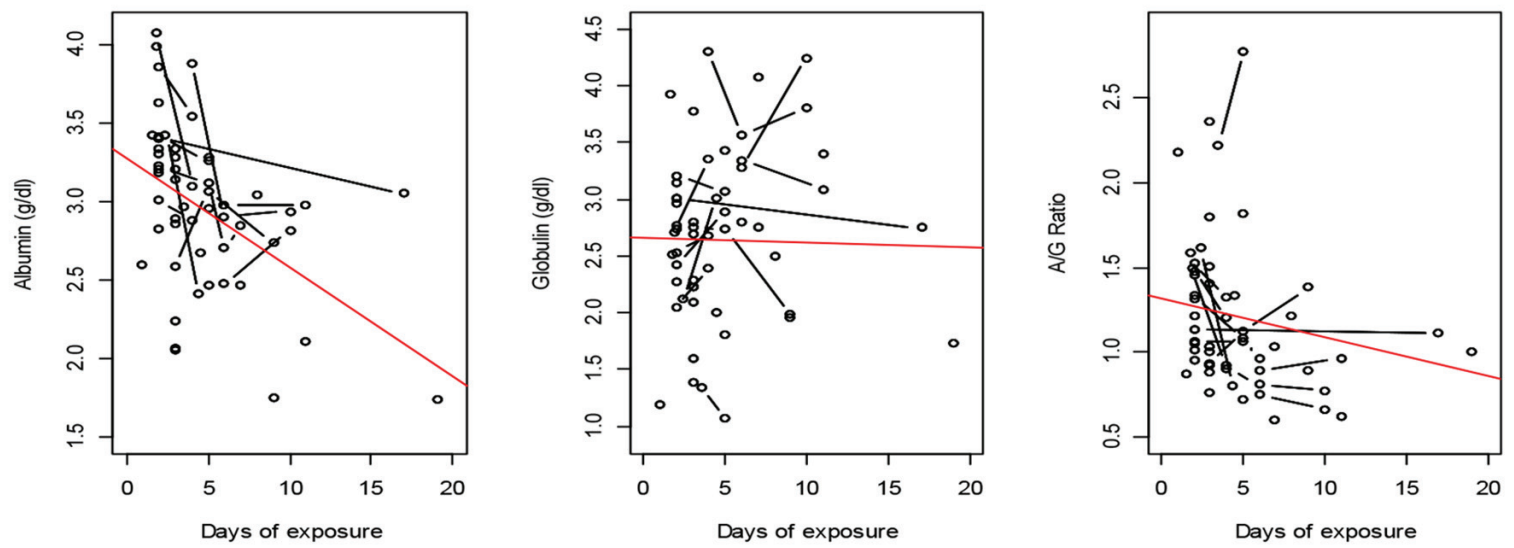

Figure 5. Plasma proteins after exposure to oxygen in GI. The observations are represented by circles, which are connected if they belong to the same patient. A fitting line represents the trend. 
Table 3. Arterial Blood Gas Measures in Patients

\begin{tabular}{llllll} 
& \multicolumn{2}{c}{ G1 } & & \multicolumn{2}{c}{ G2 } \\
\cline { 2 - 3 } \cline { 5 - 6 } & Mean $(95 \%$ CI $)$ & SD & & Mean (95\% CI) & SD \\
\hline $\mathrm{HCO}_{3}{ }^{\dagger}$ & $28.9(25.7-32.0)$ & 6.4 & & $19.6(16.9-22.4)$ & 5.4 \\
$\mathrm{FIO}_{2}$ & $51.5(41.2-61.7)$ & 14.8 & & \\
$\mathrm{PaO}_{2}$ & $73.1(53.0-93.1)$ & 40.8 & & $61.4(49.6-73.1)$ & 22.9 \\
$\mathrm{PaO}_{2} / \mathrm{FIO}_{2}$ & $184.7(102.1-267.3)$ & 125.5 & & \\
$\mathrm{PaCO}_{2}^{\dagger}$ & $44.3(38.7-49.9)$ & 11.2 & & $31.2(26.7-35.7)$ & 8.8 \\
\hline
\end{tabular}

†Significant difference between G1 and G2 at alpha $=0.05$.

tients. The prevalence rates of underweight, wasting and stunting were $45.6 \%, 33.3 \%$ and $35.1 \%$. According to WHO [21], such rates are considered high prevalences. The patients showed other evidence of protein energy malnutrition. And there was no weight gain during hospitalization in spite of the relatively long treatment period (data not shown).

We found moderate underweight $(-3 \mathrm{SD}$ to $<-2 \mathrm{SD})$ in $40.9 \%$ of all patients $<12$ months of age and in $61.5 \%$ of G1 patients $\geq 12$ months of age. Recent weight loss (wasting) is a sign of protein-calorie deficiency, indicated by low ZWH in G1 compared to G2 and C. The co-occurrence of underweight and wasting in G1 patients denoted chronic malnutrition. G2 patients exhibited a milder underweight status compared to G1. The observed low ZWA on admission agreed with the findings of others [22-25]. From a review of studies from developing countries, Victora et al [26] concluded that underweight infants have a higher risk of mortality, case fatality and morbidity from pneumonia or ALRI. In critical illness, fat is preferred over carbohydrates as a source for oxidation. Although fat stores were not evaluated in the present study, the persistent underweight in G1 patients suggests that they had diminished fat stores.

Low ZHA identifies children with stunting, which is a consequence of chronic undernutrition. Control subjects were significantly heavier, taller and had significantly higher ZHA scores than G1 and G2 patients. In G1, low ZHA was observed in $69.2 \%$ of patients $\geq 12$ months. Stunting was not detected in G2, probably because they were younger than G1 patients. The occurrence of recurrent infections and other illnesses was strongly associated with growth deficits and was coincident with a higher number of infants $<12$ months in both patient groups compared to $\mathrm{C}$. Hence, respiratory failure in G1 could have been aggravated by their early nutritional depletion.

Very severe forms of rickets were reported in $17.5 \%$ of patients compared to none of the $\mathrm{C}$ group. Eighty percent of ricketic patients required oxygen therapy. A comparable study from Ethiopia [27] showed a 13-fold higher incidence of rickets among children with pneumonia than among controls.

\section{Diarrhea}

Surprisingly, our study revealed a higher incidence of vomiting and diarrhea among G2 compared to G1 patients. This could be due to the younger age of G2 patients. Egyptian infants < 12 months have been found to have a 4.6 times higher risk of persistent diarrhea than older children [28]. The lower weight of G2 patients probably played no role since underweight is not related to diarrhea morbidity [29].

\section{Breastfeeding}

Short duration of breastfeeding and unfavorable weaning practices are common in developing countries. Breastfeeding protects babies against many types of infections during the first 6 months of life. Etiler et al (2002) [30] demonstrated that ARI was associated with non-exclusive breastfeeding and stunting. Breastfed infants showed a lower risk of morbidity and mortality from ARI [31]. Pullan et al (1980) [32] demonstrated that breastfeeding protects against viral pneumonia. In our study, breastfeeding during the early months of life was associated with shorter length of oxygen therapy $(\mathrm{P}=0.032)$.

Infection is accompanied by metabolic stress with increased production of free radical species and auto-oxidation of various biological molecules. Without sufficient antioxidant protection, oxygen therapy may constitute an additional source of oxygen free radicals. Metabolic studies show that critically ill infants with high metabolic rates have higher fat oxidation than patients with lower metabolic rates [33]. Breastfeeding provides babies with endogenous antioxidants such as uric acid and bilirubin. Thus, lack of breastfeeding could have aggravated the adverse effects of oxygen and could have contributed to the higher mortality in G1 compared to G2 patients.

\section{Total protein}

Previous studies recommended higher intakes of protein and energy for critically ill children, particularly those under 2 years of age, than for healthy children 1) to compensate for the high rate of protein turnover, 2) to meet higher basal energy requirements in infants $<2$ years of age, 3) to maintain growth [34]. Chan et al (1999) [35] showed that it is difficult to achieve positive nitrogen balance in critically ill patients on parenteral nutrition due to the ongoing catabolism. In our study, the reduced plasma total proteins in G1 
patients agree with the above suggestions. Reduced albumin levels paralleled changes in total proteins and Cer levels in G1 patients, as was found by Labeeb et al [36]. A negative nitrogen balance may be assumed for our G1 patients as they presented a higher severity of illness and had only modest protein intakes. In the study by Coss-Bu et al [33], a lower rate of protein oxidation was reported for critically ill infants with a positive nitrogen balance than for infants in negative nitrogen balance.

\section{Albumin}

Albumin determines the colloidal osmotic pressure of blood. Hypoalbuminemia $(<2.5 \mathrm{~g} / \mathrm{dL}$, up to 1 year; $<3 \mathrm{~g} / \mathrm{dL}, 1-4$ years) has been associated with increased morbidity and mortality among hospitalized patients [37]. However, low albumin concentration does not necessarily indicate poor nutritional status or loss of body mass [38]. Rather, the cause can be decreased albumin synthesis due to inflammation and metabolic stress mediated by cytokines in response to injury [39]. But most of the time hypoalbuminemia indicates a state of undernutrition.

High morbidity and mortality among hospitalized patients [37] and severe loss of body proteins [40] have been associated with hypoalbuminemia. Several authors reported a positive correlation of albumin concentration with weight, body mass index and skin fold thickness [41, 42]. Merritt et al (1985) [38] suggested that hypoalbuminemia is associated with inflammation, as in pneumonia, rather than being a common marker of protein [22] or caloric deficiencies [39]. Our data on plasma albumin during the acute phase are comparable to those obtained by many authors $[22,25,36,43]$ as they indicated a negative linear correlation between plasma albumin and the length of oxygen therapy in G1. Hypoalbuminemia during inflammation [44] and during the edematous phase of PEM (i.e., Kwashiorkor and marasmic Kwashiorkor) [45] is due to reduced synthesis. Klar et al (2003) [43] suggested that in severe infections such as pneumonia, intestinal permeability is increased which results in protein loss that could aggravate pulmonary hypertension.

The ratio of albumin to globulin in serum reflects a relative change in albumin and globulin in disease states. A lower globulin level indicates a weaker immune response. Our data showed insignificantly lower globulin levels in G1 compared to G2 and control groups. These findings agree with those of Pollack et al [46] and support the notion that attenuated functions of immune proteins are an early event in hospitalized critically ill infants, which renders younger malnourished infants more susceptible to severe respiratory distress and mortality.

\section{Copper}

Copper is an essential antioxidant trace element and is transported bound to enzymes such as the ferroxidase ceruloplas$\min (\mathrm{Cer})$ and $\mathrm{Cu}, \mathrm{Zn}$-superoxide dismutase that use $\mathrm{Cu}$ as a co-factor in electron transfer reactions. Our results revealed a significant reduction in plasma $\mathrm{Cu}$ on admission of $\mathrm{G} 1 \mathrm{com}-$ pared to $\mathrm{C}$. Serum $\mathrm{Cu}$ is not altered by marginal $\mathrm{Cu}$ deficiency, but the relatively minor decrease in plasma $\mathrm{Cu}$ in $\mathrm{G} 1$ may reflect a more serious depletion at the tissue level, similar to the observation of Karakas et al (2001) [47]. Absorbed Cu is primarily transported by plasma albumin from the intestine to the liver or to the kidney. The depressed albumin levels in the two patient groups could explain their lower $\mathrm{Cu}$ levels than those of $\mathrm{C}$ patients.

\section{Ceruloplasmin}

Iron deficiency (low ferritin) with and without anemia in young infants is a major endemic problem associated with low socioeconomic status in Egypt. Low $\mathrm{Hb}$ and iron deficiency (ferritin) were present in $73 \%$ and $38 \%$, respectively of Egyptian infants who participated in the CRSP study (reviewed [48]). Studies from an Egyptian population of underweight infants aged 6 - 36 months revealed a low iron status [34]. Iron deficiency anemia has a negative effect on physical growth. Loading of transferrin with iron is a function of Cer. Cer is an acute phase reactant, as it regulates hypoxia-inducible factor. In our study, Cer activity in G1 and G2 patients was reduced significantly compared to $\mathrm{C}$, which paralleled plasma $\mathrm{Cu}$ levels. Our results contradict those of Sobol and Pyda [49] who reported higher serum $\mathrm{Cu}$ and $\mathrm{Cer}$ values in the acute stage of pneumonia in infants aged $2-12$ months compared to healthy controls. Cer is a ubiquitous iron metabolizing antioxidant protein. As it activates oxygen, Cer antagonizes prooxidant-mediated reduction of non-protein-bound iron III to the toxic form iron II. Subsequently, Cer transfers iron II in transferrin to the bone marrow for hematopoiesis. In inflammation, while circulating levels of Cer increase, the capacity for iron transport decreases as the mobilization of $\mathrm{Fe}^{3+}$ from stores and consequently its incorporation into $\mathrm{Hb}$ is reduced.

The majority of patients in our study showed low $\mathrm{Hb} \mathrm{lev-}$ els on admission. Iron was administered to a high proportion of G1 patients as a component of parenteral nutrition, whereas the majority of G2 patients received only enteral iron. Five of our study patients demonstrated severe forms of anemia together with advanced malnutrition. Metwally et al (2000) [50] reported increased prevalence of stunting and wasting in children with anemia from slum areas in Egypt, compared to controls.

\section{Closing remarks}

Tolerance of critically ill infants to oxygen over long period of time may be altered by their underlying severe malnutrition. Nutritional support administered during the intensive care was insufficient to prevent or ameliorate the persistent malnutrition and the deteriorated immunological state in patients. The mechanism involved in the development of hypoalbuminemia in malnourished pneumonic infants can be attributed to injuries mediated by oxygen therapy. More studies need to be done to investigate whether severely undernourished young infants with severe RD need ventilation for long time. 


\section{Abbreviations}

$\mathrm{N}$ : number; G1: group 1; G2: group 2; C: control; WHZ: weight for height $\mathrm{z}$ score; HAZ: height for age $\mathrm{z}$ score; WAZ: weight for age $\mathrm{z}$ score; RD: respiratory distress; ALI: acute lung insufficiency; ARDS: acute respiratory distress syndrome; $\mathrm{PaO}_{2}$ : partial pressure of oxygen; $\mathrm{mm} \mathrm{Hg}$ : millimeter mercury; $\mathrm{SaO}_{2}$ : oxygen saturation; $\mathrm{PaCO}_{2}$ : partial pressure of carbon dioxide; $\mathrm{kPa}$ : kilopascal; $\mathrm{pH}$ : acidity (hydrogen ion concentration); $\mathrm{P} / \mathrm{F}$ ratio: arterial oxygen tension $\left(\mathrm{PaO}_{2}\right)$ /fraction of inspired oxygen $\left(\mathrm{FIO}_{2}\right)$; SD: standard deviation; NCHS/WHO: National Centre for Health Statistics/World Health Organization; SAS: Statistical Analysis Software; IV: disease severity level 4; III: disease severity level 3; P: alpha; Hb: hemoglobin; A/G ratio: albumin/globulin ratio; $\mathrm{HCO}_{3}$ : bicarbonate; PEM: protein energy malnutrition; $\mathrm{Cu}$ : copper; $\mathrm{Zn}$ : zinc; CRSP: the Nutrition Collaborative Research Support Program

\section{References}

1. Kirkwood BR, Gove S, Rogers S, Lob-Levyt J, Arthur P, Campbell H. Potential interventions for the prevention of childhood pneumonia in developing countries: a systematic review. Bull World Health Organ. 1995;73(6):793798 .

2. Williams BG, Gouws E, Boschi-Pinto C, Bryce J, Dye C. Estimates of world-wide distribution of child deaths from acute respiratory infections. Lancet Infect Dis. 2002;2(1):25-32.

3. WHO. Eastern Mediterranean Regional Office [Report]. 2010. http://www.emro.who.int/emrinfo/index. aspx?Ctry=egy.

4. WHO. Mortality Country Fact Sheet 2006. http://www. who.int/whosis/mort/profiles/mort_emro_egy_egypt.pdf.

5. James JW. Longitudinal study of the morbidity of diarrheal and respiratory infections in malnourished children. Am J Clin Nutr. 1972;25(7):690-694.

6. Yassin KM. Indices and sociodemographic determinants of childhood mortality in rural Upper Egypt. Soc Sci Med. 2000;51(2):185-197.

7. Glezen P, Denny FW. Epidemiology of acute lower respiratory disease in children. $\mathrm{N}$ Engl $\mathrm{J}$ Med. 1973;288(10):498-505.

8. Victora CG, Smith PG, Vaughan JP, Nobre LC, Lombardi C, Teixeira AM, Fuchs SM, et al. Evidence for protection by breast-feeding against infant deaths from infectious diseases in Brazil. Lancet. 1987;2(8554):319-322.

9. Gross RL, Newberne PM. Role of nutrition in immunologic function. Physiol Rev. 1980;60(1):188-302.

10. WHO. Case management of ARI in children in developing countries [Report]. 1984. Geneva.

11. WHO. The evolution of diarrheal and acute respiratory disease control at WHO. 1999. Achievements 1980-1995 in Research, Development, and Implementation. Department of Child and Adolescent Health and Development.

12. WHO. Physical status. The use and interpretation of anthropometry [WHO Technical Report Series]. 1995. 854.
13. Bernard GR, Artigas A, Brigham KL, Carlet J, Falke K, Hudson L, Lamy M, et al. Report of the AmericanEuropean consensus conference on ARDS: definitions, mechanisms, relevant outcomes and clinical trial coordination. The Consensus Committee. Intensive Care Med. 1994;20(3):225-232.

14. Jelliffe DB. The assessment of the nutritional status of the community (with special reference to field surveys in developing regions of the world). Monogr Ser World Health Organ. 1966;53:3-271.

15. Hamill PV, Drizd TA, Johnson CL, Reed RB, Roche AF. NCHS growth curves for children birth-18 years. United States. Vital Health Stat 11. 1977;(165):i-iv, 1-74.

16. Grant GH, Kachmar JF. Fundamentals of Clinical Chemistry. Tietz NW, ed. W.B. Sunders Co: Philadelphia; 1976.

17. Henry RJ, Cannon DC, Winkelman JW. Clinical chemistry, principles and techniques. 2nd edn. Harper and Row, ed. 1974.

18. Amatuzio DS, Grande F, Wada S. The cyanmethemoglobin method for hemoglobin determination. Minn Med. 1962;45:378-381.

19. Schosinsky KH, Lehmann HP, Beeler MF. Measurement of ceruloplasmin from its oxidase activity in serum by use of o-dianisidine dihydrochloride. Clin Chem. 1974;20(12):1556-1563.

20. Abe A, Yamashita S, Noma A. Sensitive, direct colorimetric assay for copper in serum. Clin Chem. 1989;35(4):552554.

21. WHO. Highlights of recent activities in the context of the world declaration and plan of action for nutrition. 1995. Nutrition Program. Geneva.

22. Prinsloo JG, Pretorius PJ. Body-weights and serum protein values of Bantu children with pneumonia. S Afr Med J. 1966;40(11):243-244.

23. Rowland $\mathrm{MG}$, Rowland $\mathrm{SG}$, Cole TJ. Impact of infection on the growth of children from 0 to 2 years in an urban West African community. Am J Clin Nutr. 1988;47(1):134-138.

24. Almeida Santos L, Ruza F, Guerra AJ, Alves A, Dorao P, Garcia S, Santos NT. Nutritional evaluation of children with respiratory failure (RF): anthropometric evaluation upon admission to the pediatric intensive care units. An Esp Pediatr. 1998;49(1):11-16.

25. Delgado AF, Kimura HM, Cardoso AL, Uehara D, Carrazza FR. Nutritional follow-up of critically ill infants receiving short term parenteral nutrition. Rev Hosp Clin Fac Med Sao Paulo. 2000;55(1):3-8.

26. Victora CG, Kirkwood BR, Ashworth A, Black RE, Rogers S, Sazawal S, Campbell H, et al. Potential interventions for the prevention of childhood pneumonia in developing countries: improving nutrition. Am J Clin Nutr. 1999;70(3):309-320.

27. Muhe L, Lulseged S, Mason KE, Simoes EA. Casecontrol study of the role of nutritional rickets in the risk of developing pneumonia in Ethiopian children. Lancet. 1997;349(9068):1801-1804.

28. Yassin K. Morbidity and risk factors of diarrheal diseases among under-five children in rural Upper Egypt. J Trop Pediatr. 2000;46(5):282-287. 
29. WHO. World health report. Reducing risks, promoting healthy life. 2002. Chapter 4 Quantifying selected major risks to health, Underweight. Page 2.

30. Etiler $\mathrm{N}$, Velipasaoglu S, Aktekin $\mathrm{M}$. Incidence of acute respiratory infections and the relationship with some factors in infancy in Antalya, Turkey. Pediatr Int. 2002;44(1):64-69.

31. Jason JM, Nieburg P, Marks JS. Mortality and infectious disease associated with infant-feeding practices in developing countries. Pediatrics. 1984;74(4 Pt 2):702-727.

32. Pullan CR, Toms GL, Martin AJ, Gardner PS, Webb JK, Appleton DR. Breast-feeding and respiratory syncytial virus infection. Br Med J. 1980;281(6247):1034-1036.

33. Coss-Bu JA, Klish WJ, Walding D, Stein F, Smith EO, Jefferson LS. Energy metabolism, nitrogen balance, and substrate utilization in critically ill children. Am J Clin Nutr. 2001;74(5):664-669.

34. Curley MA, Castillo L. Nutrition and shock in pediatric patients. New Horiz. 1998;6(2):212-225.

35. Chan S, McCowen KC, Blackburn GL. Nutrition management in the ICU. Chest. 1999;115(5 Suppl):145S$148 \mathrm{~S}$.

36. Labeeb RA, Abd-Elmotaleb FI, Essa S, Nasser MF. The role of some enzymatic and nonenzymatic antioxidants in protein energy malnutrition. The Egyptian Journal of Biochemistry and Molecular Biology. 2004;22:78-92.

37. Reinhardt GF, Myscofski JW, Wilkens DB, Dobrin PB, Mangan JE Jr., Stannard RT. Incidence and mortality of hypoalbuminemic patients in hospitalized veterans. JPEN J Parenter Enteral Nutr. 1980;4(4):357-359.

38. Merritt RJ, Kalsch M, Roux LD, Ashley-Mills J, Siegel SS. Significance of hypoalbuminemia in pediatric oncology patients - malnutrition or infection? JPEN J Parenter Enteral Nutr. 1985;9(3):303-306.

39. Doweiko JP, Nompleggi DJ. Role of albumin in human physiology and pathophysiology. JPEN J Parenter Enteral Nutr. 1991;15(2):207-211.

40. Hansen JD, Schendel HE, Wilkins JA, Brock JF. Nitrogen metabolism in children with kwashiorkor receiving milk and vegetable diets. Pediatrics. 1960;25:258-282.

41. Mokni R, Chakar A, Bleiberg-Daniel F, Mahu JL, Walravens PA, Chappuis P, Navarro J, et al. Decreased serum levels of nutritional biochemical indices in healthy children with marginally delayed physical growth. Acta Paediatr. 1993;82(6-7):539-543.

42. Shaaban SY, Marzouk D, Nassar MF, Ezzat NI, Mohamed I. Early detection of protein energy malnutrition in Sharkia Governorate. J Egypt Public Health Assoc. 2005;80(5-6):665-685.

43. Klar A, Shoseyov D, Berkun Y, Brand A, Braun J, Shazberg $\mathrm{G}$, Jonathan $\mathrm{M}$, et al. Intestinal protein loss and hypoalbuminemia in children with pneumonia. J Pediatr Gastroenterol Nutr. 2003;37(2):120-123.

44. Gabay C, Kushner I. Acute-phase proteins and other systemic responses to inflammation. $\mathrm{N}$ Engl $\mathrm{J}$ Med. 1999;340(6):448-454.

45. Waterlow JC. Amount and rate of disappearance of liver fat in malnourished infants in Jamaica. Am J Clin Nutr. 1975;28(11):1330-1336.

46. Pollack MM, Wiley JS, Holbrook PR. Early nutritional depletion in critically ill children. Crit Care Med. 1981;9(8):580-583.

47. Karakas Z, Demirel N, Tarakcioglu M, Mete N. Serum zinc and copper levels in southeastern Turkish children with giardiasis or amebiasis. Biol Trace Elem Res. 2001;84(1-3):11-18.

48. Allen LH. Malnutrition and human function: a comparison of conclusions from the INCAP and nutrition CRSP studies. J Nutr. 1995;125(4 Suppl):1119S-1126S.

49. Sobol G, Pyda E. Copper and ceruloplasmin concentrations in serum of infants with pneumonia. Pneumonol Alergol Pol. 1995;63(7-8):378-381.

50. Metwally AM, Ibrahim NA, Shabaan FA, El Sayed HM. Nutritional deficiencies and parasitic infection interaction among children in slum areas in Cairo, Egypt. Egyptian J of Nutrition. 2000; XV(2):15-45. 